\title{
Neuroinflammation after Intracerebral Hemorrhage and Potential Therapeutic Targets
}

\author{
Christine Tschoe, ${ }^{\text {a }}$ Cheryl D. Bushnell, ${ }^{\mathrm{b}}$ Pamela W. Duncan, ${ }^{\mathrm{b}, \mathrm{c}}$ Martha A. Alexander-Miller, ${ }^{\mathrm{d}}$ \\ Stacey Q. Wolfe \\ aDepartment of Neurological Surgery, Wake Forest School of Medicine, Winston-Salem, NC, USA \\ bDepartment of Neurology, Wake Forest Baptist Health, Winston-Salem, NC, USA \\ 'Department of Gerontology and Geriatric Medicine, Wake Forest School of Medicine, Winston-Salem, NC, USA \\ dDepartment of Microbiology and Immunology, Wake Forest School of Medicine, Winston-Salem, NC, USA
}

\begin{abstract}
Spontaneous intracerebral hemorrhage $(\mathrm{ICH})$ is a catastrophic illness causing significant morbidity and mortality. Despite advances in surgical technique addressing primary brain injury caused by $\mathrm{ICH}$, little progress has been made treating the subsequent inflammatory cascade. Pre-clinical studies have made advancements identifying components of neuroinflammation, including microglia, astrocytes, and T lymphocytes. After cerebral insult, inflammation is initially driven by

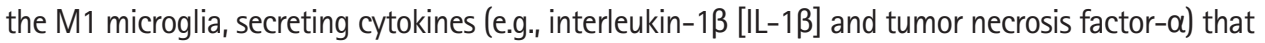
are involved in the breakdown of the extracellular matrix, cellular integrity, and the blood brain barrier. Additionally, inflammatory factors recruit and induce differentiation of $A 1$ reactive astrocytes and Thelper 1 (Th1) cells, which contribute to the secretion of inflammatory cytokines, augmenting $\mathrm{M} 1$ polarization and potentiating inflammation. Within 7 days of $\mathrm{ICH}$ ictus, the $\mathrm{M} 1$ phenotype coverts to a M2 phenotype, key for hematoma removal, tissue healing, and overall resolution of inflammation. The secretion of anti-inflammatory cytokines (e.g., IL-4, IL-10) can drive Th2 cell differentiation. M2 polarization is maintained by the secretion of additional antiinflammatory cytokines by the Th2 cells, suppressing M1 and Th1 phenotypes. Elucidating the timing and trigger of the anti-inflammatory phenotype may be integral in improving clinical outcomes. A challenge in current translational research is the absence of an equivalent disease animal model mirroring the patient population and comorbid pathophysiologic state. We review existing data and describe potential therapeutic targets around which we are creating a bench to bedside translational research model that better reflects the pathophysiology of ICH patients.
\end{abstract}

Keywords Cerebral hemorrhage; Stroke; Neuroinflammation; Immunomodulation; Fingolimod hydrochloride; Programmed death-1

\author{
Correspondence: Christine Tschoe \\ Department of Neurological Surgery, \\ Wake Forest School of Medicine, 1 \\ Medical Center Blvd., Winston- \\ Salem, NC 27101, USA \\ Tel: +1-336-713-5929 \\ Fax: +1-336-716-3065 \\ E-mail: ctschoe@wakehealth.edu
}

Received: August 28, 2019

Revised: September 30, 2019

Accepted: October 18, 2019

\section{Introduction}

Spontaneous intracerebral hemorrhage $(\mathrm{ICH})$ is a catastrophic illness representing a global public healthcare problem. Of the 15 million strokes reported worldwide annually, ICH accounts for approximately $10 \%$ to $15 \%$ of all stroke cases in the United Statement, Europe, and Australia; and approximately 20\% to $30 \%$ of strokes in Asia. ${ }^{1}$ This is associated with a 40\% 30-day mortality rate, ${ }^{2}$ and those who survive have major neurologic deficits, with only around $20 \%$ of patients reaching functional 
independence at 6 months. ${ }^{3}$ Although there has been a significant reduction in overall age-adjusted incidence of stroke, the incidence of ICH has remained unchanged in the past 40 years. ${ }^{2}$ In the United Statement alone, the annual healthcare costs of ICH is estimated at $\$ 12.7$ billion. $^{4}$

Hospitalizations for ICH have increased by $18 \%$ in the last decade ${ }_{1}^{5}$ likely due to the aging population and the increasing use of anticoagulants and antiplatelet therapy. The most important risk factor is age. With each advance in decade after the age of 50, there is a 2-fold increase in $\mathrm{ICH}$ incidence. ${ }^{6} \mathrm{ICH}$ due to hypertension (HTN) accounts for approximately $65 \%$ of all spontaneous $\mathrm{ICH}^{7.8} \mathrm{ICH}$ in the setting of HTN and associated co-morbid states including diabetes mellitus, coronary and cerebrovascular disease, and renal insufficiency, commonly occurs in the deep cerebral locations (basal ganglia, thalamus), followed by cerebral lobes, cerebellum, and brainstem (predominantly pons). ${ }^{6} \mathrm{ICH}$ in the setting of cerebral amyloid angiopathy usually presents in a lobar location. Other causes of $\mathrm{ICH}$ include neoplasms, arteriovenous malformations and fistulae, cerebral cavernous malformations, and aneurysms. ${ }^{7}$

Primary brain injury from ICH typically occurs within the first few hours of ictus and is due to hematoma formation, leading to mechanical damage of the adjacent tissues from dissection and compression. Hemorrhagic volume is an important factor in determining ICH outcome, with hemorrhage volumes $>100$ $\mathrm{mL}$ associated with worse prognosis, often with high intracranial pressure, decreased cerebral blood flow and brain herniation. ${ }^{9}$ Location of the ICH is also important for outcome, and while guidelines support the evacuation of cerebellar hemorrhage as potentially life and function saving, thalamic hemorrhage has a notoriously poor outcome despite treatment. ${ }^{10} \mathrm{Al}-$ though recent minimally invasive surgical approaches to hematoma removal while limiting surgical morbidity are underway with promising results, this does not address the secondary brain injury following $\mathrm{ICH}^{1{ }^{11-15}}$

Complex immune and inflammatory cascades occur in response to acute cerebral insults, including $\mathrm{ICH} .{ }^{16}$ Microglia, astrocytes, and T lymphocytes work in concert to be key modulators of the inflammatory response both in ischemic stroke and ICH. Based on a growing body of evidence, activated microglia appear to be the main source of cytokines, chemokines, prostaglandins, and other immunomodulatory molecules that can potentiate or attenuate secondary brain injury and are involved in subsequent brain repair mechanisms. ${ }^{16}$ In order to identify potential therapeutic targets and effectively treat the inflammatory sequelae of $\mathrm{ICH}$, we need to better understand the timing of the inflammatory response and the interplay between the cellular and molecular components in post-ICH secondary brain injury and repair.

This review will summarize the recent body of evidence describing the inflammatory cell populations and molecular signaling following $\mathrm{ICH}$. As will be discussed, there are several targets that could prove efficacious in the amelioration of secondary brain injury after ICH. However, a common challenge in much of the current translational research is the absence of an equivalent disease animal model. Most of the current data is from healthy, young male animal models that do not represent the older age, sex, and comorbidities of the patient population affected by $\mathrm{ICH}$. By better understanding the existing body of literature, we can create a comprehensive bench to bedside translational research model that would better reflect the pathophysiology and affected population of ICH.

\section{Neuroinflammation}

Secondary injury, such as cerebral edema, plays a significant role in the neurologic decline of $\mathrm{ICH}$ patients. ${ }^{17}$ This is triggered by the presence of intraparenchymal blood, which activates cytotoxic, excitotoxic, oxidative, and inflammatory pathways (Figure 1). ${ }^{18}$ There is an immediate inflammatory response after the presence of blood components are detected within the parenchyma, characterized by the mobilization and activation of inflammatory cells. It is believed that the microglia and astrocytes are the earliest of the inflammatory cells to respond to extravasated blood. ${ }^{19}$ The activation of microglia leads to infiltration of various circulating immune cells, most notably macrophages and T cells. This subsequently leads to the release of

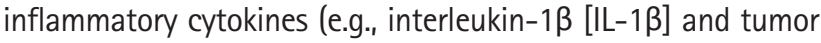
necrosis factor- $\alpha[$ TNF- $\alpha])$, chemokines, free radicals, and other potentially toxic chemicals that are coordinated via the transcription factor nuclear factor- $\mathrm{KB}$ (NF-KB) ${ }^{16} \mathrm{NF}-\mathrm{KB}$ targets include the genes of cytokines, chemokines, various adhesion molecules, cell surface receptors, and inflammatory enzymes (e.g., inducible nitric oxide synthase [iNOS], cyclooxygenase-2 [COX-2], phospholipase A2 [PLA2]). ${ }^{20}$ These chemicals, together with cell death products, further activate resident and migrating lymphocytes, leading to increased infiltration of lymphocytes and a continued cycle of inflammatory response. There is increasing evidence that this inflammatory response contributes to the formation of edema through increased blood brain barrier (BBB) permeability around the hematoma, which exacerbates mass effect, augments the cell death process through secondary ischemia, and further produces inflammatory insults to the surrounding brain tissue. ${ }^{21}$ Although it would be appropriate to present the inflammatory cascade in a temporal fashion, it is presently difficult to do given the current incomplete 

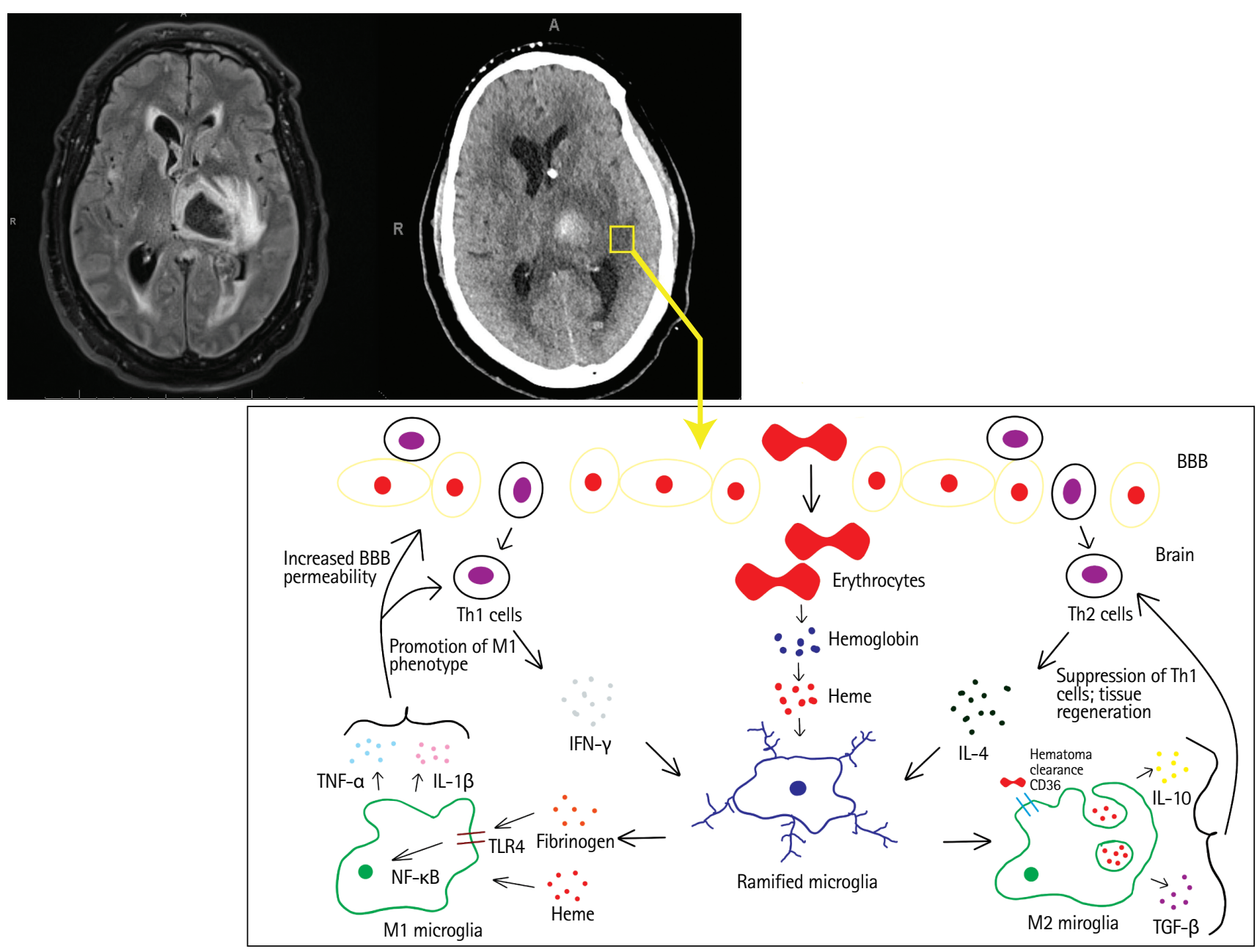

Figure 1. Magnetic resonance imaging fluid attenuated inversion recovery (left) and computed tomography (right) illustrating cerebral edema surrounding the primary intracerebral hemorrhage. Cerebral edema is the result of the ongoing inflammatory response occurring in the presence of the breakdown products of the hematoma. The initial pro-inflammatory phase involves the activation of M1 microglia, upregulating the production of interleukin-1 13 (IL-1 $\beta$ ), tumor necrosis factor- $\alpha$ (TNF- $\alpha$ ), and other inflammatory products that are involved in potentiating cellular damage and the breakdown of the blood brain barrier (BBB). Once the M2 microglia are activated, there is release of anti-inflammatory cytokines IL-4, IL-10, and transforming growth factor- $\beta$ (TGF- $\beta$ ), all in-

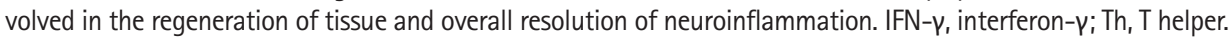

understanding of the mechanism. Instead, we will focus on three cellular components of the innate and adaptive immune systems as it relates to the two phases of inflammatory response associated with injury: the pro-inflammatory/cytotoxic phase (M1 microglia, A1 astrocytes, T helper 1 [Th1] and Th17 cells) and the anti-inflammatory/neuroprotective phase (M2 microglia, Th2 and T regulatory (Treg) cells) (Figure 1).

\section{Cellular components of the innate immune system}

\section{Microglia}

Microglia are the resident macrophages of the central nervous system (CNS) and account for approximately 5\% to 20\% of the total CNS glial population. ${ }^{22}$ They continually surveil the brain for infection and damage; and play an important role in the in- flammatory and recovery phases of injury. In the non-activated state, they move frequently with intermittent extension of fine processes to assess and sample the microenvironment. ${ }^{23}$ They quickly activate to respond to changes in their environment induced by factors secreted by neurons and astrocytes. Once activated, they gather around the site of damage or pathogen, develop stout processes, and become highly phagocytic. ${ }^{21}$

Microglia are vital in maintaining homeostasis of the CNS, including clearance of pathogens, damaged CNS tissue, and remodeling of the extracellular matrix and synapses. ${ }^{24}$ Microglia also play a critical role in overall brain development and adult learning (activity-triggered synaptic plasticity). ${ }^{25-27}$ Following activation, microglia appear morphologically indistinguishable from infiltrating macrophages. However, recent studies revealed a receptor specific to microglia; P2Y12, an ad- 
enosine diphosphate/adenosine triphophate (ADP/ATP)-responsive G-protein coupled receptor, can be found on the resting, ramified processes of surveillant microglia. ${ }^{28,29}$ Extracellular ATP, when released from damaged neurons, acts as a danger signal, and upon binding with microglial P2Y12, causes migration of microglia to the site of injury. ${ }^{30,31}$

Once tissue damage occurs, microglia can be activated within minutes via neurotoxins released into the extracellular space by necrotic neurons. ${ }^{32}$ By 72 hours, microglia/macrophage numbers have reached their peak. ${ }^{19}$ By day 7 , the numbers begin to reduce, and by 21 days, the microglia/macrophages have returned to baseline numbers (Figure 2 ). ${ }^{33}$

Based on ischemic injury and traumatic brain injury models, two microglia phenotypes have been identified. The M1 phenotype is considered pro-inflammatory/injury-inducing and is

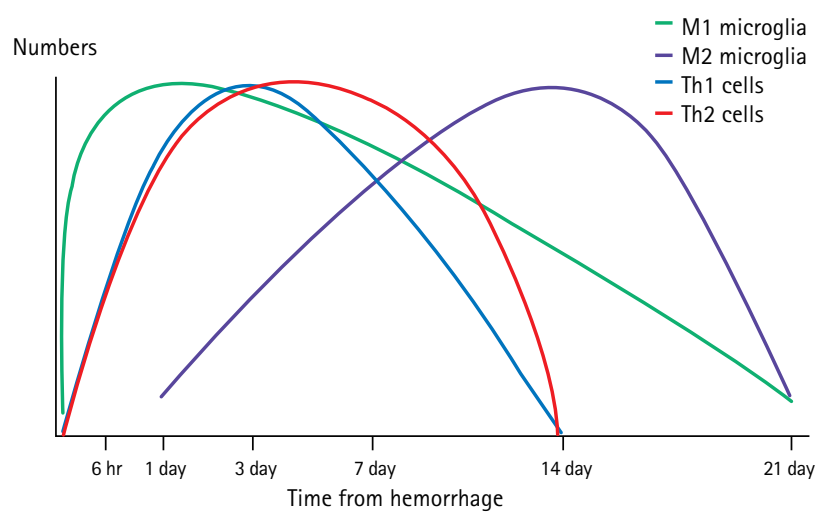

Figure 2. Timeline of inflammatory cells after intracerebral hemorrhage. These timelines are based on young, healthy male animal models with data based on normal immune responses. When accounting for age and comorbidities, the timing and activation of different immune cells may differ in the target population of patients with intracerebral hemorrhage. Th, T helper. known to produce inflammatory cytokines (IL-1 $\beta, I L-12, I L-23$, and TNF- $\alpha$ ), chemokines, nitric oxide (NO), and reactive oxygen species which initiate breaking down the BBB. ${ }^{32,34}$ Their macrophage markers include CD86, CD16, major histocompatibility complex (MHC) II, and iNOS (Table 1)..$^{24}$ The M2 phenotype is considered to be anti-inflammatory and is generally involved in phagocytosis, release of trophic factors, and the overall regeneration of tissue and resolution of inflammation. ${ }^{35}$ The presence of anti-inflammatory cytokine IL-4 can prime the polarization to the M2 phenotype, leading to the production of IL10 and upregulation of surface phenotype markers arginase-1 (Arg-1), CD206, Ym-1, and CD36 (Table 2). ${ }^{35}$

In ischemic stroke murine models, it has been noted that both phenotypes are present at the site of injury, with a transient initial $\mathrm{M} 2$ activation giving way to a predominance of the M1 phenotype within the first week of injury. ${ }^{36}$ Upregulation of M1related genes (iNOS, CD11b, CD16, CD32, and CD86) is seen from day 3 to 14 post-stroke. Conversely, mRNA expression for M2 markers (e.g., CD206, Arg-1, Ym-1/2, IL-10, transforming growth factor- $\beta$ [TGF- $\beta]$ ) is observed on day 1 , peaks around day 3 to 5 , and returns to pre-injury levels by day $14 .{ }^{37}$ In contrast to ischemic stroke, ICH murine models have demonstrated a rapid increase in M1 microglia within 6 hours of ictus that slowly decreases over 14 days, whereas the M2 phenotype was found at low levels at day 1 and increased over 14 days. ${ }^{38,39}$ Fol-

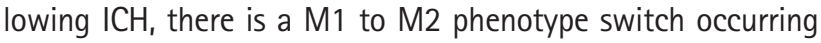
within the first 7 days, but the exact timing and driving force of the phenotype change remains unclear. ${ }^{35}$ The microglia have a great deal of plasticity, allowing variation between phenotypes based on cues from the microenvironment. 36,40

Table 1. M1 microglia functions

\begin{tabular}{|c|c|c|c|}
\hline Phenotype & Molecule & Type & Role \\
\hline \multirow[t]{11}{*}{ M1 } & IFN- $\gamma$ & Cytokine & Pro-inflammatory, induces M1 phenotype \\
\hline & IL-1 $\beta$, IL-6, IL-23, TNF- $\alpha$ & Cytokine & Pro-inflammatory \\
\hline & IL-12 & Cytokine & Implicated in the differentiation to Th1 cells \\
\hline & IL-17 & Cytokine & Pro-inflammatory, modulating factor of cytokine production \\
\hline & ROS, iNOS & Metabolic enzyme & Oxidative damage \\
\hline & CD11b, CD16, CD32 & Surface receptors & Phagocytosis, chemotaxis \\
\hline & CD68 & Surface receptor & Scavenger receptor \\
\hline & CD86 & Surface receptor & Surface receptor interacting with CD28 \\
\hline & $\mathrm{MHCll}$ & Surface receptor & Presentation of extracellular proteins \\
\hline & $\mathrm{NF}-\mathrm{kB}$ & Transcription factor & Involved in the modification of the M1 phenotype \\
\hline & STAT1, STAT3 & Transcription factor & Promote the expression of NF-KB/p65 \\
\hline
\end{tabular}

IFN- $\gamma$, interferon- $\gamma$; IL, interleukin; TNF- $\alpha$, tumor necrosis factor- $\alpha$; Th1, T helper 1 ; ROS, reactive oxygen species; iNOS, inducible nitric oxide synthase; MHCII, major histocompatibility complex II; NF-kB, nuclear factor-kB; STAT, signal transducer and activator of transcription. 
(1) Classically activated microglia (M1 phenotype)

Classically activated microglia/M1 cells have been strongly associated with worsening cerebral edema surrounding ICH seen on radiography. ${ }^{41}$ Upon activation, M1 cells transiently develop a primarily phagocytic function to clear necrotic neurons and cellular debris to diminish the deleterious release of inflammatory cytokines and chemoattractants. ${ }^{42}$ However, as the number of M1 cells increases, the phagocytic ability appears to significantly decrease, and there is increased secretion of inflammatory cytokines, chemokines, and other neurotoxic mediators (e.g., NO), leading to widespread cellular damage. ${ }^{35}$ Additionally, proteolytic enzymes (e.g., metalloproteinases and collagenases) lead to the breakdown of the extracellular matrix and cellular integrity. ${ }^{43}$ In the ramified resting state, microglia play a role in angiogenesis and development of the BBB ${ }^{44}$ Following insult, oxidative stress from activated microglia likely plays an important role in the impairment of the $\mathrm{BBB}{ }^{44}$ Other suggested mechanisms of $\mathrm{BBB}$ hyperpermeability in the setting of $\mathrm{ICH}$ include the excessive production of NO induced by the presence of hemoglobin ${ }^{45}$ and thrombin-induced injury via the activation of proteinase activated receptor-1 (PAR-1) mechanisms. ${ }^{46}$ In the setting of increased BBB permeability, the secretion of M1specific chemokines allow infiltration and recruitment of hematogenous leukocytes that perpetuate the inflammatory response, aggravating neuronal death induced by excitotoxicity or oxygen-glucose deprivation. ${ }^{47}$ Additionally, M1 microglia can also create microglia-T cell crosstalk via antigen presentation through the M1 surface MHCIl expression. ${ }^{48}$

M1 microglia are activated following hemorrhage via dam- age-associated molecular pattern molecules (DAMPs), including the high mobility group box 1 (HMGB1), family of extracellular peroxiredoxin proteins, galactin-3, other danger signals such as hemoglobin, heme, and methemoglobin. ${ }^{23,49}$ These are sensed by the family of Toll-like receptors (TLR), present at low levels on ramified microglia and vigorously upregulated during activation. ${ }^{50}$ Upregulation of TLR4 and subsequent activation of the TLR4-mediated NF-KB pathway have been seen in ICH animal models $s^{51,52}$ and are associated with poor outcomes. ${ }^{53}$ Once TLR4 binds to its ligands, it interacts with the adaptor proteins myeloid differentiation primary response protein (MyD88) and TIRdomain-containing adapter-inducing interferon- $\beta$ (TRIF) in order to activate two parallel signaling pathways that initiate the activation of transcription factors to regulation pro-inflammatory cytokine genes. The MyD88 pathway is crucial for the activation of the NF-kB pathway, ${ }_{1}^{54}$ which occurs within 15 minutes of ICH ictu ${ }^{55}$ with subsequent upregulation of downstream target genes of IL- $1 \beta$, TNF- $\alpha$, and heme oxygenase- $1 .{ }^{20}$

\section{(2) Alternatively activated microglia (M2 phenotype)}

In the face of anti-inflammatory cytokines, specifically IL-4, IL10, and IL-13, microglia can undergo alternative activation to the M2 phenotype, resulting in hematoma/debris removal, healing (extracellular matrix deposition), neurogenesis/angiogenesis, and neuroprotection, which correlates with resolution of cerebral edema and neurologic improvement. The M2 phenotype can be broken down into subtypes M2a, M2b, and M2c, each with their unique biologic functions and cell surface markers. ${ }^{56}$ IL-4 and IL-13 can induce downstream processes

Table 2. M2 microglia functions

\begin{tabular}{|c|c|c|c|}
\hline Phenotype & Molecule & Type & Role \\
\hline \multirow[t]{12}{*}{ M2 } & $\mathrm{IL}-4$ & Cytokine & Anti-inflammatory, induces M2 phenotype \\
\hline & IL-10 & Cytokine & Anti-inflammatory, human cytokine synthesis inhibitory factor \\
\hline & TGF- $\beta$ & Cytokine & $\begin{array}{l}\text { Regulation of lymphocyte proliferation, differentiation, and survival; regeneration; upregulate } \\
\mathrm{Bcl}-2 \text { and } \mathrm{Bcl}-\mathrm{x} 1\end{array}$ \\
\hline & $Y m-1$ & Protein & Binds heparin/heparin sulfate, possibly prevents the degradation of extracellular components \\
\hline & Arg1 & Protein & Downregulation of nitric oxide synthesis. Induces fibrosis and tissue regeneration \\
\hline & $\mathrm{FlZZ1}$ & Protein & Associated with reconstruction of extracellular matrix \\
\hline & CD36 & Surface receptor & Scavenger receptor involved in hematoma resorption in setting of upregulation of PPAR- $\nu$ \\
\hline & CD163 & Surface receptor & Scavenger receptor for haptoglobin-hemoglobin complex \\
\hline & CD206 & Surface receptor & Antigen internalization and processing/mannose receptor type 1 \\
\hline & PPAR- $\nu$ & Transcription factor & Induce M2 phenotype \\
\hline & STAT6 & Transcription factor & Inhibit the activation of NF-KB \\
\hline & SOCS3 & Signaling modulator & Cytokine-inducible negative regulators of cytokine signaling \\
\hline
\end{tabular}

IL, interleukin; TGF- $\beta$, transforming growth factor- $\beta$; Bcl-2, B-cell lymphoma 2; Bcl-x1, B-cell lymphoma-extra large; Arg1, arginase 1; FIZZ1, found in inflammatory zone 1 ; PPAR- $\gamma$, peroxisome proliferator-activated receptor- $\gamma$; STAT6, signal transducer and activator of transcription 6 ; NF- $\mathrm{kB}$, nuclear factor- $\mathrm{kB}$; SOCS3, suppressor of cytokine signaling 3. 
with anti-inflammatory properties, such as Arg-1 upregulation (important part of wound healing and matrix deposition), NF$\mathrm{KB}$ isoform inhibition (leading to inhibition of the M1 phenotype), ${ }_{1}^{57}$ and increased production of scavenger receptors, such as $C D 36$ via upregulation of the transcription factor peroxisome proliferator-activated receptor $\gamma$ (PPAR- $\gamma)$, a key component of phagocytosis of extravasated erythrocytes and overall hematoma resorption. ${ }^{58-60}$ These functions have been described as the M2a activation, the opposite of the M1 phenotype with described roles in suppression of inflammation ${ }^{61}$ and contribution to cellular regeneration. ${ }^{62} \mathrm{~A}$ second phenotype, $\mathrm{M} 2 \mathrm{c}$, becomes active when exposed to IL-10, TGF- $\beta$, and glucocorticoids, which is involved in remodeling (via removal of dysfunctional synapses to allow formation of new functional synapses ${ }^{63}$ ) and matrix deposition once inflammation is downregulated. ${ }^{35} \mathrm{~A}$ third M2 sub-phenotype, M2b, has been described in the last stage of injury and is the least understood. It appears to have both pro-inflammatory and anti-inflammatory properties, but most closely resembling the M1 phenotype. They lack the typical M2 markers such as Arg-1, Ym-1, or found in inflammatory zone 1 (FIZZ1), but express the usual anti-inflammatory cytokine IL-10. 35,56,62 They also appear to have higher levels of MHCII and CD86, suggesting they have retained the ability to stimulate T cells and initiate the $\mathrm{M} 2$ response. $^{64} \mathrm{M} 2 \mathrm{~b}$ activation also leads to the in recruitment of regulatory $T$ cells. ${ }^{65}$

Recent studies have described a family of transcription factors known as signal transducer and activator of transcription (STAT) that serve as crucial signals to achieve M1 or M2 polarization. ${ }^{66}$ Generally speaking, the STATs are activated by Janus kinase (JAK) and inhibited by feedback inhibitors called suppressor of cytokine signaling (SOCS). STAT1 increases M1 polarization in the presence of interferon- $\gamma($ IFN- $-\gamma) .{ }^{67-69}$ Conversely, STAT6 helps establish the M2 phenotype once activated by IL-13 and IL-4. ${ }^{70,71}$ The functions of STAT3 are more diverse and appear to have both pro- and anti-inflammatory roles ${ }^{66,72}$ through $\mathrm{M} 1$ polarization in the setting of IL- $6^{73}$ and $\mathrm{M} 2$ polarization in the setting of IL-10.74

Because of the anti-inflammatory function of M2 microglia, there have been efforts to find pharmacologic agents that could inhibit M1 activation, driving microglia towards the M2 phenotype. Current agents under investigation include the hypoglycemic drug class thiazolidinediones (rosiglitazone and pioglitazone), which act as PPAR- $\gamma$ receptor agonists. In support of this approach, preclinical autologous ICH models have demonstrated thiazolidinedione-mediated decreases in the production of pro-inflammatory factors, driving M2 activation. ${ }^{75}$ Experimental treatment in these models has shown upregulation of CD36 expression with improved hematoma resolution, de- creased pro-inflammatory gene expression, and reduction in subsequent neuronal damage. ${ }^{60}$ Another agent under investigation is the tetracycline antibiotic minocycline. In in vitro models, minocycline was found to inhibit the upregulation of $N F-K B$, indicating selective inhibition of $\mathrm{M} 1$ activation without affecting the expression of M2 markers. ${ }^{76}$ Minocycline also reduces the early upregulation of pro-inflammatory factors such as TNF- $\alpha$ and matrix metalloproteinases (MMPs). ${ }^{77}$

\section{Astrocytes}

There is emerging evidence that there is another key cellular component of neuroinflammation. Astrocytes are abundant within the CNS and perform the following key functions: (1) neurotrophic support; (2) synaptogenesis and maintenance of these synapses; (3) synaptic pruning; and (4) control of BBB functions, including bidirectional control of blood flow and neuronal function and restricting the entry of immune cells. ${ }^{78}$ Activated microglia induce the activation of astrocytes and will determine their functional fate, either neuroprotective or detrimental for neuronal function. Conversely, astrocytes also secrete pro-inflammatory (e.g., IL-1 $\beta$, IL-6) and anti-inflammatory cytokines that can control the activation and functions of microglia. ${ }^{79}$ The pro-inflammatory state induced by M1 microglia, the A1 astrocytes, can lead to the upregulation and expression of pro-inflammatory cytokines, chemokines, and growth factors. ${ }^{80}$ This results in abnormal neurotransmitter synthesis and release, synaptic destruction, and loss of other homeostatic functions, specifically, the failure to promote neuronal growth and survival and the release of neurotoxins, leading to apoptosis of neurons and surrounding oligodendrocytes. ${ }^{81}$ It has been hypothesized that there is an A2 astrocyte state that is induced under ischemic conditions, encouraging upregulation of neurotrophic factors and the secretion of proteins promoting synpatogenesis. ${ }^{82}$

Astrocytes have been observed to accumulate in the perihematomal region within 1 to 3 days after $\mathrm{ICH}$ ictus. ${ }^{83}$ There are several mechanisms by which reactive $\mathrm{A} 1$ astrocytes may be detrimental in the setting of ICH. The presence of hemoglobin in the brain parenchyma is a powerful trigger of oxidative stress, which then induces MMP-9 on astrocytes. ${ }^{84}$ MMPs have been implicated in blood barrier injury and subsequent cerebral edema in $\mathrm{ICH}^{.5}$ Another consequence of blood extravasation on astrocytes is the presence of thrombin in the extracellular matrix, which also induces cerebral edema after $\mathrm{ICH}^{7}$ and leads to the activation of PAR-1, which can be primarily found at perisynaptic endfeet of the astrocyte. ${ }^{86}$ In addition to causing further cerebral injury, PAR-1 on astrocytes causes rapid remodeling of synapses, resulting in migration of astrocytic pro- 
cesses away from excitatory glutamatergic synapses. ${ }^{87}$ This reduction of glutamatergic receptors in the setting of astrocytic PAR-1 impairs long-term plasticity. ${ }^{87}$ This particular detrimental mechanism may be involved in the cognitive impairment that is seen after ICH. Although we have evidence that suppression of astrocytic activity decreases hematoma volume, BBB destruction, and improves neurologic outcomes, ${ }_{1}^{88}$ therapeutic targets as it relates to astrocytes have not been explored and warrant further investigation.

\section{Cellular components of the adaptive immune system}

\section{Tlymphocytes}

T lymphocyte functions have been well-characterized in ischemic stroke models, ${ }_{1}^{89}$ but their role in $\mathrm{ICH}$ is less defined. As such, much of our understanding of T cell function in $\mathrm{ICH}$ is extrapolated from pre-clinical ischemic models. In the healthy brain, there are very low numbers of T cells functioning in CNS surveillance. ${ }^{90}$ Those present appear to enter the cerebrospinal fluid through choroid plexus veins or meningeal blood vessels to monitor the subarachnoid space, allowing for initiation of a local immune response or return to secondary lymphoid organs. ${ }^{91}$ Following stroke, immunohistochemistry has identified different T cell subtypes invading the infarcted region. It is theorized that activated T cells can cross the BBB once a T cell response is activated in the presence of a CNS autoantigen in the lymphoid organs..$^{92}$ In the ischemic stroke model, the influx of $\mathrm{CD} 4^{+}$and $\mathrm{CD}^{+} \mathrm{T}$ cells are thought to play a detrimental role in perpetuating ischemic tissue injury by contributing to the microvascular dysfunction caused by cerebral ischemia/reperfusion injury. ${ }^{93}$ Models of either $\mathrm{CD}^{+}$or $\mathrm{CD}^{+}$deficiency resulted in decreased stroke volume and improved neurologic performance. ${ }^{18,94}$ Alternatively, some types of T cells can play a neuroprotective role, such as regulatory $T$ cells following ischemia, which promote recovery via their immunomodulating properties..$^{95,96}$

Temporally, there have been reports of an increase in $\mathrm{CD} 8^{+}$ cytotoxic T cells as early as 24 hours after ICH, peaking after 2 to 7 days. ${ }^{97}$ There is an increase in CD4 ${ }^{+}$Th cells approximately 3 to 4 days after a hemorrhagic event. ${ }^{98}$ Guo et al. ${ }^{99}$ confirm the presence of Th cells in the perihematomal region in surgical specimens of patients with ICH. These data support the radiographic findings of cerebral edema, with peak swelling days 3 to 7 after ICH.

Th cell differentiation in CNS injury and neuroregeneration has been an area of extensive research. In the 1980's, two subtypes of $\mathrm{CD}^{+} \mathrm{T}$ cells were described based on their cytokine secretion patterns: Th1 and Th2 cells (Table 3). ${ }^{90}$ Th1 cells are programmed to fight intracellular pathogens by supporting cell-mediated responses, including cytotoxic $T$ cells and natural killer (NK) cells. ${ }^{100}$ Th1 cell differentiation is initiated by IL-12 and IFN- $\gamma$, known to perpetuate pro-inflammatory reactions. These cells are typically characterized by $\mathrm{C}-\mathrm{C}$ chemokine receptor type 5 (CCR5), C-X-C motif chemokine receptor 3 (CXCR3), and T-bet markers. ${ }^{101} \mathrm{~T}$-bet is the primary transcription factor to determine the Th1 phenotype by upregulating the production of IFN- $\gamma$ and plays an important role in suppressing differentiation to Th2 and Th17 cell types. ${ }^{102-104}$ Additionally, there is an IL-12 induced STAT4 pathway that promotes Th1 differentiation. These 2 pathways work in tandem rather than in a sequential fashion. ${ }^{102}$ Although the Th1 cells are known to be present within the perihematomal region, their role in the pathogenesis of $\mathrm{ICH}$-induced secondary injury remains to be defined. It is theorized that these cells promote vascular permeability and may induce apoptosis of neurons via production of inflammatory cytokines. ${ }^{92}$ Th2 cells function to fight extracellular pathogens via the humoral response and are critical for wound healing and repair ${ }^{105}$ following the time course of radiographic evolution of edema from post-bleed day 7 onward. Their differentiation is typically initiated by IL-4 and IL-2, and they secrete IL-4, IL-5, IL-6, IL-9, IL-10, and IL-13, which are involved in various anti-inflammatory functions. Th2 cells can be identified by CCR3, CCR4, chemoattractant receptor-homologous molecule (CRTH2), and transcription factor GATA binding protein 3 (GATA3) expression. ${ }^{101}$ STAT6 is the primary transcription factor involved in the Th2 cell differentiation through upregulation of GATA3. ${ }^{106}$ It is presumed that Th2 cells act by producing the above cytokines to down-regulate, and in some cases, directly suppress Th1 cell activation. ${ }^{92}$ Given the delayed infiltration of Th cells, ${ }^{98}$ it is postulated that they directed the later stages of the immune response after ICH, fostering either a highly inflammatory microenvironment or a regenerative microenvironment. However, we currently lack the preclinical evidence for the exact role of these T-helper subtypes.

Another set of functionally opposing lymphocytes involved in the inflammatory response in ICH is Th17 and Treg cells. This set of cells has a reciprocal relationship in the promotion and suppression of inflammation. Th17 cells differentiate in the presence of IL-6, IL-21, IL-23, and TGF- $\beta$. These cells express CCR6 and RORyt markers and secrete IL-17, IL-21, and IL-22. Th17 cells have been strongly linked to various autoimmune diseases (e.g., multiple sclerosis [MS]) via production of IL-17 and IL-22. It is theorized that a key pathophysiologic mechanism is the disruption of the BBB via binding of cytokines secreted by Th17 cells to IL-17 and IL-22 receptors found on endothelial cells, allowing for the further recruitment and migration of Th 17 cells 
Table 3. T lymphocyte populations and functions

\begin{tabular}{|c|c|c|c|}
\hline Phenotype & Molecule & Type & Role \\
\hline \multirow[t]{3}{*}{ Th1 } & IL-12, TNF- $\alpha$ & Cytokine & $\begin{array}{l}\text { Activates macrophages, responsible for cell-mediated immunity and phago- } \\
\text { cyte-dependent protective responses }\end{array}$ \\
\hline & T-bet & Transcription factor & $\begin{array}{l}\text { Induces Th1 phenotype, enhances production of IFN- } \gamma \text { and mediates repression } \\
\text { of IL-4 expression }\end{array}$ \\
\hline & STAT1 & Transcription factor & $\begin{array}{l}\text { Primarily regulates T-bet and mediates IL-4 repression to mediate Th1 cell } \\
\text { commitment }\end{array}$ \\
\hline \multirow[t]{5}{*}{ Th2 } & IL-4, IL-5, IL-10, IL-13 & Cytokines & $\begin{array}{l}\text { Responsible for strong antibody production, eosinophil activation, and inhibi- } \\
\text { tion of several macrophage functions, providing phagocyte-independent pro- } \\
\text { tective responses }\end{array}$ \\
\hline & GATA3 & Transcription factor & Key for Th2 cytokine production; inhibition of Th1 responses \\
\hline & STAT3 & Transcription factor & Required by STAT6 for interaction with appropriate gene loci \\
\hline & STAT5 & Transcription factor & Independent of IL-4 signaling; coordinates with GATA3 to induce Th2 phenotype \\
\hline & STAT6 & Transcription factor & Upregulates expression of GATA3 and mediates Th2 cell phenotype \\
\hline \multirow[t]{3}{*}{ Th17 } & IL-17A/F, IL-21, IL22, IL-23, TGF- $\beta$ & Cytokines & $\begin{array}{l}\text { Creates inflammation and tissue injury in autoimmune diseases; unclear of } \\
\text { function in ICH }\end{array}$ \\
\hline & RORyt & Transcription factor & Master regulator to induce Th17 phenotype via STAT3 activation \\
\hline & STAT3 & Transcription factor & Activated by IL-6 and IL-23 to induce expression of RORyt \\
\hline \multirow[t]{3}{*}{ Treg } & IL-2, IL-10, TGF- $\beta$ & Cytokines & $\begin{array}{l}\text { Essential for the maintenance of peripheral tolerance, prevention of autoim- } \\
\text { mune disease, and limiting chronic inflammatory disease }\end{array}$ \\
\hline & Foxp3 & Transcription factor & Major lineage-specific transcription factor involved in Treg differentiation \\
\hline & STAT5 & Transcription factor & Enhances Foxp3 expression to promote Treg development \\
\hline
\end{tabular}

Th, T helper; IL, interleukin; TNF- $\alpha$, tumor necrosis factor- $\alpha$; IFN- $\gamma$, interferon- $\gamma$; STAT, signal transducer and activator of transcription; GATA3, GATA binding protein 3 ; TGF- $\beta$, transforming growth factor- $\beta$; ICH, intracerebral hemorrhage; ROR $\gamma t$, retinoic acid receptor-related orphan receptor $\gamma t$; Foxp3, forkhead box P3; Treg, T regulatory.

and other pathogenic cell types, including Th1 cells..$^{107}$ However, the actual role of Th17 cells in the pathophysiology of post- $\mathrm{ICH}$ neuroinflammation remains unknown. Th17 cells express a high degree of plasticity, allowing for functional adaptation and phenotypic switching to Treg cells depending on the inflammatory milieu. TGF- $\beta$ alone can induce the differentiation of Treg cells, or conversely, in combination with IL-6 or IL-21, can lead to the differentiation of Th17 cells. ${ }^{108}$

Treg cells are known for their anti-inflammatory function by mediating immune tolerance to self-antigens. Existing data suggest that Treg cells are beneficial in the context of stroke, both ischemic and hemorrhagic. Depletion of Treg cells led to increased brain injury and neurologic deterioration ${ }^{95}$ and boosting the presence of Treg cells decreased ICH-induced inflammatory injury. ${ }^{96}$ In a rat ICH model, Treg transfusion resulted in the inhibition of IL-1 $\beta$, TNF- $\alpha$, and MMP- 2 in the perihematomal tissue and increased the presence of the anti-inflammatory cytokines IL-4, IL-10, and TGF- $\beta$. $^{109}$ Transfused Treg cells decreased perihematomal edema and BBB permeability, leading to improved short- and long-term neurologic function. ${ }^{10}$

It is clear that the function of microglia and T cells are intertwined, i.e., they have the potential to cross-regulate the differentiation and phenotype of the other population. ${ }^{49,102}$ This occurs largely through the production of cytokines. M1 cells produce TNF- $\alpha, \mathrm{IL}-6, \mathrm{IL}-12$, and IL-23, ${ }^{111}$ which can recruit and induce the differentiation of Th1 and Th17 cells. In a positive feedback loop, Th1 cells secrete IFN- $\gamma$ and Th17 cells secrete IL-17, continuing the cycle of augmenting M1 polarization and potentiating the inflammatory response. ${ }^{112}$ Similarly, M2 cells secrete IL-4, IL-10, and TGF- $\beta$, which drives differentiation into Th2 and Treg cells. As a result, M2 polarization is maintained by the production of IL-4 and IL-10 by Th2 cells and IL-10 and TGF- $\beta$ by Treg cells. This results in downregulation of the inflammatory response and promotes tissue repair. ${ }^{101}$ In a murine autologous injection ICH model, Treg cells have been seen to modulate microglia activation and polarization with decreased expression of TNF- $\alpha$, IL-1 $\beta$, MMP-2, pro-inflammatory cytokines and chemokines necessary for the activation of microglia, particularly the M1 phenotype. ${ }^{113}$ Similarly, boosting the Treg population increased the presence of M2 associated markers (TGF- $\beta$ and IL-10) with a resultant increase in CD206 expression, indicating increased conversion to M2 phenotype of microglia, therefore ameliorating ICH-induced inflammatory injury. ${ }^{114}$

Other cells of the adaptive immune system

To date, there is very little literature regarding the pathophysi- 
ologic role of B cells and NK cells after ICH. It has been observed there is minimal CNS infiltration of these 2 cell types after $\mathrm{ICH}_{1}^{115}$ indicating a minor role in the neuroinflammatory process after ICH.

\section{Programmed death-1 pathway}

Programmed death-1 (PD-1) is a member of the CD28 family of $\mathrm{T}$ cell regulators and functions as a negative regulatory system to fine-tune $T$ and $B$ cell activity and plays a critical role in the maintenance of central and peripheral immune tolerance. The PD-1 pathway is essential for the maintenance of peripheral $T$ cell tolerance and is crucial in the attenuation of autoimmunity and preservation of T cell homeostasis. It is expressed at low levels on naïve T cells, and can be induced in most immune cells upon activation. $.^{18} \mathrm{PD}-1$ binds 2 ligands, programmed death-ligand 1 (PD-L1-CD274) (found on T cells, B cells, dendritic cells, NK cells, macrophages, monocytes, and non-hematopoietic cells) and PD-L2 (CD273). PD-L1 expression is upregulated in the presence of several pro-inflammatory factors, including TNF- $\alpha$, types I and II IFNs, granulocyte-macrophage colony-stimulating factor, vascular endothelial growth factor, IL-4, and IL-10, of which IFN- $\gamma$ is the most potent. ${ }^{116}$

The PD-1/PD-L1 ligation complex mediates immune suppression via several mechanisms. First, the PD-1 complex can lead to the inactivation of $\mathrm{T}$ cells. The presence of PD-L1 on antigen presenting cells (APCs) is key in the induction and maintenance of anergy of autoreactive T cells. ${ }^{117}$ The binding of PD-L1 to PD-1 blocks the downstream signaling events that occur after $\mathrm{T}$ cell receptor (TCR)-mediated cell activation, impairing $\mathrm{T}$ cell activation (block of T cell proliferation) and IL-2 production. ${ }^{118}$ The PD-1/PD-L1 complex also decreases T cell survival by impacting genes involved in apoptosis. This pathway prevents the expression of the anti-apoptotic gene B-cell lymphoma $\mathrm{X}_{\mathrm{L}}(\mathrm{BCl}-$ $X_{L}$ ) and upregulates the pro-apoptotic factor Bim..$^{119}$ Finally, the PD-1 pathway is key in the generation of anti-inflammatory Treg cells. PD-L1+ APCs, in the presence of TGF- $\beta$, can convert naïve peripheral CD4+ T cells to inducible Treg cells. ${ }^{119}$ PD-L1 maintains the survival and anti-inflammatory activity of Treg cells by upregulating the expression of the Treg transcription factor forkhead box P3 (Foxp3). Additionally, mature Th1 cells can be converted to Foxp3+ Tregs cells by engaging the PD-1 pathway. PD-1 deficiency or PD-1/PD-L1 blockade can lead to the development or exacerbation of autoimmune diseases. ${ }^{120}$ In addition to its regulatory activity on lymphocytes, the PD-1/ $\mathrm{PD}-\mathrm{L} 1$ interaction may also regulate the function of macrophages, leading to increased IL-10 (anti-inflammatory) and decreased IL-6 (pro-inflammatory) production. ${ }^{121,122}$
Again, much of the work highlighting the importance of PD-1 and PD-L1 signaling in post-stroke inflammation first comes from studies in the pre-clinical ischemic stroke animal model. In a murine experimental stroke model (transient middle cerebral artery occlusion [MCAO] in 8 to 12 week old otherwise healthy male animals) after a 96-hour reperfusion period, Upregulation of PD-1 expression was observed in resident microglia and macrophages within the ischemic CNS lesion on wild-type (WT) mice, and was not seen in PD-1 knockout (KO) mice. ${ }^{114}$ The loss of PD-1 led to significantly increased numbers of MHC class II+ and TNF- $\alpha$ secreting microglia and macrophages after activation, resulting in larger infarct volumes and worsened neurologic deficit, compared to WT animals with an intact PD-1 pathway. ${ }^{114}$ Alternatively, the same research group performed another study with PD-L1 and PD-L2 KO mice and noted that the presence of PD-Ls exacerbated post-stroke inflammation, increased infarct size, and worsened neurologic outcomes. ${ }^{123}$ Mechanistically, the protective effect of PD-1 may be due to its expression on $B$ cells and resulting inhibition of other immune effectors cells, and the detrimental effect of PDL1 may be due to its ability to inhibit recruitment of immunoregulatory $C D 8+C D 122+$ suppressor $T$ cells from the spleen into the brain. ${ }^{124}$

In contrast, a mouse collagenase injection ICH model has shown upregulation of PD-1 expression in the perihematomal tissues, expressed mainly on macrophages, and in PD-1 KO mice, there was significant increase in mRNA and protein expression of pro-inflammatory cytokines compared to WT ICH groups, manifesting as increased brain water content and worsened neurologic impairment in the PD-1 KO group. ${ }^{125}$ PD-L1 administration significantly attenuated the severity of neurologic deficits, decreased cerebral edema by decreasing brain water content, and decreased hemorrhage volume. ${ }^{126}$ PD-L1 also downsized the number of $\mathrm{CD}^{+}{ }^{+} \mathrm{T}$ cells infiltrating the brain and overall percentages of Th1 and Th17 cells while increasing the overall percentages of the Th2 and regulatory $T$ cells. The overall pro-inflammatory cytokine production was decreased with down-regulation of IL-1 $\beta$, IL- 6 , and TNF- $\alpha$, and upregulation of IL-10. ${ }^{126}$

As mentioned earlier, microglia polarization plays a very important role in $\mathrm{ICH}$-induced secondary brain injury. In response to $\mathrm{ICH}$, selective polarization to the pro-inflammatory type occurs. ${ }^{127}$ Overexpression of PD-1/PD-L1 was able to decrease this pro-inflammatory phenotype, with evidence of inhibited STAT1 phosphorylation, suggesting a possible method of modulation to the anti-inflammatory phenotype via inhibition of STAT1 (Figure 3). ${ }^{127}$

The PD-1 pathway, as it relates to stroke, warrants further investigation as a therapeutic target to drive the phenotypic 


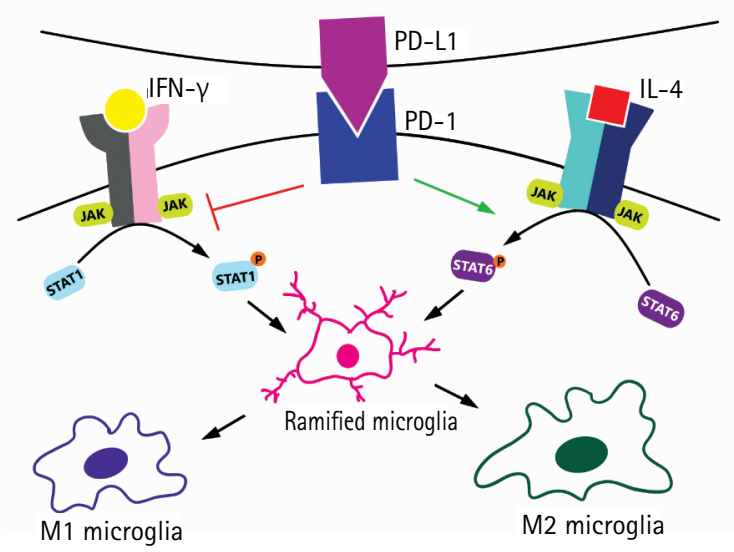

Figure 3. Programmed death-1 (PD-1)/programmed death-ligand 1 (PD-L1) driven polarization of microglia. In the setting of intracerebral hemorrhage, upregulation of PD-1 has been noted in the perihematomal tissue. After the administration of PD-L1, the overall number of T cells infiltrating the central nervous system was decreased, with decreased total T helper 1 (Th1) and Th17 cells and increased Th2 and T regulatory cells. There is also increased polarization to the $\mathrm{M} 2$ phenotype in the setting of signal transducer and activator of transcription 1 (STAT1) inhibition. IFN- $\gamma_{\text {, interferon- }-\gamma \text {; }}$ JAK, Janus kinase; IL-4, interleukin-4.

change from a pro- to anti-inflammatory immune profile in order to mediate perihematomal edema and improve overall outcomes. As noted, there is discrepancy in the function of the PD-1 pathway in the neuroinflammatory process between acute ischemic stroke (AIS) and spontaneous ICH, as well as discrepancy within the AIS literature itself. As a result, there is a need for a model of stroke, both ischemic and hemorrhagic, that can be used to better understand this pathway in the context of the actual disease state, which includes associated risk factors and co-morbidities that are representative of a lowlevel chronic pro-inflammatory state.

\section{Sphingosine 1-phosphate receptor modulation}

Sphingosine 1-phosphate (S1P) engagement of sphingosine 1-phosphate receptors (S1PRs) plays a key role in the regulation of immune responses. In vivo, sphingosine is phosphorylated by sphingosine kinase 1/2 (Sphk1/2) to S1P, which then binds to Gprotein coupled receptors S1PRs. There are five known S1PR subtypes, S1PR $1-5$. S1PRs $1-3$ are universally expressed in the immune, cardiovascular, and CNSs. S1PR, and to a lesser extent $\mathrm{S}_{1 R_{3}}$ and $\mathrm{S}_{1} \mathrm{PR}_{4}$, is highly expressed on $\mathrm{T}$ and $\mathrm{B}$ lymphocytes. $\mathrm{S}_{1 P R}$ is generally found in the hematopoietic and lymphoid tissues. S1PR5 is predominantly found within the CNS white matter. ${ }^{128}$ This family of receptors participate in a wide variety of biologic processes, including leukocyte recirculation, cellular pro- liferation and differentiation, morphologic changes, cellular motility, endothelial cell function, vascular regulation, and cardiovascular and nervous system development. ${ }^{129}$

The role of the S1P/S1PR axis in the control of T cell retention in lymph nodes has been extensively studied. ${ }^{130}$ In naïve T cells, S1PR 1 expression directs lymphocyte egress from lymph nodes in responses to the high concentration of S1P ligand present at exit sites. ${ }^{131}$ Following T cell activation, $\mathrm{S}_{\mathrm{PR}}$ expression is transiently decreased, inhibiting egress during the period of proliferation and differentiation. Upon re-expression of $\mathrm{S}_{\mathrm{PR}}$, activated T cells leave to traffic to sites of infection/ inflammation. ${ }^{131} \mathrm{~S} 1 \mathrm{P}$ also plays an important role in modulating Treg differentiation and function. S1P binding has been reported to inhibit differentiation into Treg cells as well as decrease suppressive activity, ${ }^{132}$ making this pathway an important potential contributor to the immune response following CNS damage.

Fingolimod (FTY720) is a structural analogue of phosphorylated sphingosine. It acts as a S1PR modulator and functions to regulate various cellular responses, including proliferation, apoptosis, and inflammation. ${ }^{128}$ It binds with a high affinity to the following S1PR subtypes: S1PR $, \mathrm{S}_{1} \mathrm{PR}_{3}, \mathrm{~S}_{1} \mathrm{PR}_{4}$, and $\mathrm{S}_{1} \mathrm{PR}_{5 .}{ }^{128}$ Fingolimod is an oral immunomodulatory agent approved by the U.S. Food and Drug Administration for the treatment of relapsing-remitting MS, in which it has been shown to reduce relapses and limit loss of brain volume. ${ }^{133-135}$ The classic mechanism of fingolimod is based on the control mechanism of $\mathrm{T}$ cell retention and egress. It acts as a functional antagonist at S1PR1, causing internalization and degradation of this receptor and removing the lymphatic S1P gradient necessary for lymphocyte egress, thereby reducing the overall number of inflammatory cells migrating to the CNS. ${ }^{136}$ Based on the high expression of S1PRs in the CNS, a new aspect of fingolimod function is emerging, focusing on direct neurologic cellular modulation. It has been found to easily cross the blood-brain barrier in its unphosphorylated form, where it is then phosphorylated by endogenous CNS Sphk2. ${ }^{128}$ Once phosphorylated, it is postulated that fingolimod has the capacity to influence the function of CNS biology by reducing astrogliosis and demyelination. ${ }^{137}$

S1PRs are widely expressed on all cell lines in the CNS, although the level of receptor subtype expression varies based on cell type, and in the case of microglia, their state of activation. ${ }^{138}$ In the ramified state, microglia express S1P receptors 1 , 2,3 , and 5 , with $\mathrm{S} 1 \mathrm{PR}_{1}$ expression being the dominant receptor type. ${ }^{128}$ S1P signaling is essential in key neuron specific functions such as the regulation of transmitter release and the proliferation and survival of neurons and glia. ${ }^{139}$ It has been re- 


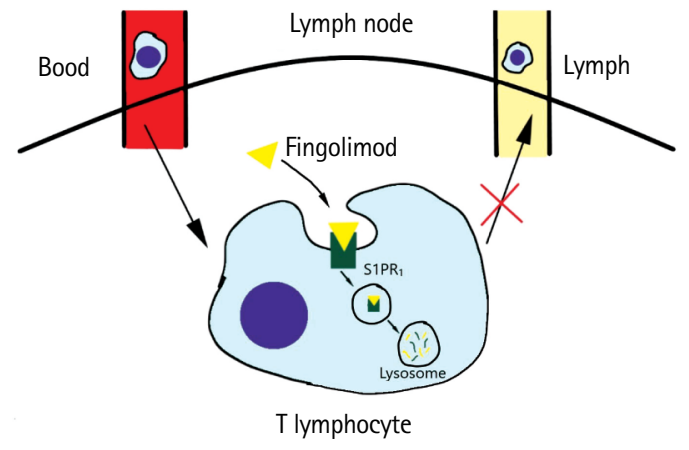

(A)
Microglia: $\mathrm{S}_{\mathrm{PR}}>\mathrm{S}_{1} \mathrm{PR}_{2}>\mathrm{S}_{\mathrm{PR}} \mathrm{R}_{3,5}$

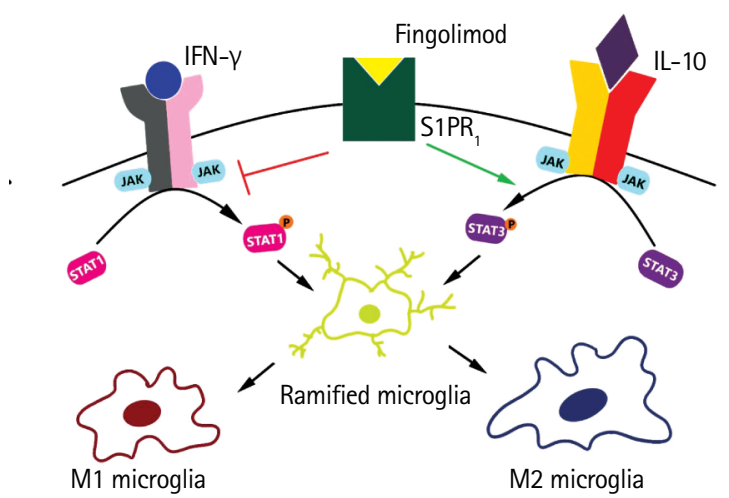

B

Figure 4. Fingolimod's proposed anti-inflammatory functions. (A) The sphingosine 1-phosphate (S1P) and sphingosine 1-phosphate receptor 1 (S1PR 1 ) interactions on lymphocytes are key for exiting the lymph nodes. In the inactivated state, S1PR undergoes cyclical expression on circulating T cells. In the blood and lymph, S1PRs are typically downregulated in the presence of a high concentration of S1P. When the T cells circulate within the lymph nodes, S1PR expression is upregulated in the setting of low S1P concentrations. If an appropriate antigen is not encountered, T cells will exit, following the gradient of S1P. In the setting of fingolimod, the receptors internalize and are degraded. This prevents the sensing of the S1P gradient, thereby preventing the egress of the T cells. (B) In the central nervous system, $\mathrm{S} 1 \mathrm{PR}_{1}$ is noted to be expressed in high concentrations on microglia. It is proposed that fingolimod increases the expression and phosphorylation of signal transducer and activator of transcription 3 (STAT3) and inhibiting STAT1, potentiating the polarization the M2 phenotype. IFN- $\gamma$, interferon- $\gamma$; JAK, Janus kinase; IL-10, interleukin 10.

ported that Sphk1 plays a critical part in the inflammatory processes mediated by TNF- $\alpha$ in immune cells. ${ }^{140}$ In vitro, once microglia have been activated, S1P has been noted to amplify the release of pro-inflammatory cytokines, and with the suppression of Sphk1, there was suppression of TNF- $\alpha, \mathrm{IL}-1 \beta$, and iNOS gene expression. ${ }^{141}$ This was confirmed in vitro with the binding of S1PRs with fingolimod, which downregulated the production of pro-inflammatory cytokines and promoted the increased expression and release of neurotrophic factors. The effect on gene expression was also shown to be dose-dependent. ${ }^{142,143}$

In addition to regulation of inflammatory and chemoattractant molecule gene expression, functional antagonism of the S1PRs with fingolimod may also limit the inflammatory response of activated microglia by polarizing microglia to the M2 phenotype, which suggests that S1P could be involved in the activation of the JAK/STAT3 cascade that is typically associated with M2 polarization (Figure 4). ${ }^{144}$ Additionally, gene expression profiling has been performed to better understand the molecular effects of fingolimod. It has been found that fingolimod inhibited the expression of critical transcription factors, most importantly STAT1, thereby suppressing the activation of microglia (M1 phenotype). ${ }^{145}$ The effect of fingolimod on microglial activation was confirmed in vivo in MS patients, where serial positron emission tomography imaging was performed, showing decreased microglial activation at the sites of focal inflammatory lesions. ${ }^{146}$
Based on literature showing fingolimod and its protective effects on ischemia-reperfusion injury in heart, liver, and kidney, ${ }^{147,148}$ several groups hypothesized a potential neuroprotective effect of fingolimod in the setting of cerebral ischemia. It showed a neuroprotective effect after MCAO in the rat model with significantly diminished infarct volume, improved overall neurologic scores at 24 and 72 hours $^{149}$ and fewer activated neutrophils and microglia/macrophages. ${ }^{150}$ Based on this preclinical evidence, two small human pilot studies were recently performed to evaluate the safety and efficacy of fingolimod in the treatment of acute ischemic strokes. Their clinical results mirrored those seen in animal models, with reduced infarct size and improved clinical outcomes. ${ }^{151}$

Beyond ischemic insults, fingolimod has also been shown to potentially reduce the incidence of reperfusion hemorrhage in the setting of delayed tissue plasminogen activator administration via enhancement of the BBB integrity. ${ }^{152}$ In light of this evidence, Lu et al. ${ }^{153}$ studied the effects of fingolimod in the setting of ICH in the mouse model. It was found that fingolimod significantly reduced perihematomal edema, apoptosis, and associated brain atrophy, but they did not find a difference in the number of inflammatory cells between the treated and control groups. ${ }^{153}$ However, Rolland et al..$^{154}$ found significant reduction in hematogenous and intracerebral lymphocytes compared to controls. They also found decreased expression of intercellular adhesion molecule-1 (ICAM-1), IFN- $\gamma$, and IL-17 
at 72 hours. At 8 and 10 weeks post-ICH, treated rats were noted to have significantly reduced spatial and motor learning deficits, brain atrophy, and neuronal cell loss. ${ }^{154}$ In experimental ICH models, selective S1PR 1 immunomodulation led to significant attenuation of neurologic deficits and improved post$\mathrm{ICH}$ survival. Overall lesion volume was reduced. Decreased edema and midline shift were noted on magnetic resonance imaging, most likely due to the resultant reduced counts of microglia and T cells with associated decreased production of pro-inflammatory cytokines IL-1 $\beta$ and TNF- $\alpha$. ${ }^{155}$

A small clinical pilot study of fingolimod in $\mathrm{ICH}$ patients also exhibited radiographic evidence of smaller perihematomal edema, significant reduction in neurologic impairment and improvement in Glasgow Coma Scale by day 7; and at 3 months, a greater proportion of fingolimod-treated patients achieved full neurologic recovery. There were no differences in adverse event rates between the treated and control groups. ${ }^{156}$

\section{Summary and future directions}

Given the devastating nature of $\mathrm{ICH}$, there has been increased interest in treating both the primary $\mathrm{ICH}$ and resultant cerebral edema. It has become increasingly clear that the cellular and molecular components of inflammation are involved in posthemorrhagic secondary brain injury and are key components to the overall outcome of ICH. However, as mentioned previously, much of the current evidence regarding the inflammatory response surrounding ICH has been gleaned from healthy, young male murine models with normal immune responses. Given that age and specific medical co-morbidities are associated with the development of spontaneous ICH, we must develop $\mathrm{ICH}$ animal models that better mimic the clinical disease, as these factors may affect the inflammatory pathways and the switch from the pro-inflammatory to anti-inflammatory state. Additionally, it is important to note that current animal models do not account for differences in sex and the likely hormonal influences on the inflammatory pathways, warranting future investigations in both male and female animal models. In order to improve on the translation of preclinical findings into effective therapeutic targets, we are currently investigating the utility of the hypertensive transgenic rat line TGR (mREN2)27 in conjunction with autologous blood injection to simulate $\mathrm{ICH}$. These animals overexpress renin and become chronically severely hypertensive around week 12 . As they age, they also develop the other hallmarks of metabolic syndrome (obesity, insulin resistance, and dyslipidemia) and end organ changes (heart failure, chronic renal failure). ${ }^{157}$ As we are discovering the importance of inflammation in these chronic conditions, we are now discovering that the different factors in metabolic syndrome most likely represent a chronic low-level inflammatory state. ${ }^{158}$ As such, we believe that the presence of these chronic conditions in an animal model may yield a better understanding of neuroinflammation after ICH.

Translation of preclinical findings to the clinical setting remains challenging, in part due to current ICH animal models' limitations and incomplete understanding of the pathophysiology of this complex disease. It is clear that there are pro- and anti-inflammatory phenotypes that may be leveraged in the treatment of $\mathrm{ICH}$. With the advancement in surgical technology and techniques allowing for safe evacuation of the hemato$m a$, it is possible to define the immune cell populations and phenotypes in ICH patients and follow their inflammatory profiles over time, ultimately correlating the change from pro- to anti-inflammatory phenotypes with long-term functional status to better understand the relationship of inflammation to clinical outcomes and utilize therapeutic targets to drive this change. Modulation of described and new pathways as promising therapeutic targets, such as S1PR and PD-1/PD-L1, and the optimal timing for intervention to mitigate the inflammatory cascade surrounding $\mathrm{ICH}$ prove hopeful to improve patients' functional outcomes.

\section{Disclosure}

The authors have no financial conflicts of interest.

\section{References}

1. Qureshi Al, Mendelow AD, Hanley DF. Intracerebral haemorrhage. Lancet 2009;373:1632-1644.

2. van Asch CJ, Luitse MJ, Rinkel GJ, van der Tweel I, Algra A, Klijn CJ. Incidence, case fatality, and functional outcome of intracerebral haemorrhage over time, according to age, sex, and ethnic origin: a systematic review and meta-analysis. Lancet Neurol 2010:9:167-176.

3. Fogelholm R, Murros K, Rissanen A, Avikainen S. Long term survival after primary intracerebral haemorrhage: a retrospective population based study. J Neurol Neurosurg Psychiatry 2005;76:1534-1538.

4. Writing Group Members, Lloyd-Jones D, Adams RJ, Brown TM, Carnethon M, Dai $S$, et al. Heart disease and stroke statistics-2010 update: a report from the American Heart Association. Circulation 2010;121:e46-e215.

5. Qureshi Al, Suri MF, Nasar A, Kirmani JF, Ezzeddine MA, Divani $A A$, et al. Changes in cost and outcome among US patients with stroke hospitalized in 1990 to 1991 and those 
hospitalized in 2000 to 2001. Stroke 2007;38:2180-2184.

6. Adeoye 0, Broderick JP. Advances in the management of intracerebral hemorrhage. Nat Rev Neurol 2010;6:593-601.

7. Xi G, Keep RF, Hoff JT. Mechanisms of brain injury after intracerebral haemorrhage. Lancet Neurol 2006;5:53-63.

8. Ariesen MJ, Claus SP, Rinkel GJ, Algra A. Risk factors for intracerebral hemorrhage in the general population: a systematic review. Stroke 2003;34:2060-2065.

9. Broderick JP, Brott TG, Duldner JE, Tomsick T, Huster G. Volume of intracerebral hemorrhage: a powerful and easy-touse predictor of 30-day mortality. Stroke 1993;24:987-993.

10. Hemphill JC 3rd, Greenberg SM, Anderson CS, Becker K, Bendok BR, Cushman $M$, et al. Guidelines for the management of spontaneous intracerebral hemorrhage: a guideline for healthcare professionals from the American Heart Association/American Stroke Association. Stroke 2015;46:20322060.

11. Mould WA, Carhuapoma JR, Muschelli J, Lane K, Morgan TC, McBee NA, et al. Minimally invasive surgery plus recombinant tissue-type plasminogen activator for intracerebral hemorrhage evacuation decreases perihematomal edema. Stroke 2013;44:627-634.

12. Mendelow $A D$, Gregson BA, Rowan EN, Murray GD, Gholkar $A$, Mitchell PM, et al. Early surgery versus initial conservative treatment in patients with spontaneous supratentorial lobar intracerebral haematomas (STICH II): a randomised trial. Lancet 2013;382:397-408.

13. Minimally Invasive Surgery Plus Rt-PA for ICH Evacuation Phase III (MISTIE-III). ClinicalTrials.gov. https://ClinicalTrials. gov/show/NCT01827046. 2019. Accessed November 27, 2019.

14. MIND: Artemis in the Removal of Intracerebral Hemorrhage. ClinicalTrials.gov. https://ClinicalTrials.gov/show/NCT03342664. 2019. Accessed November 27, 2019.

15. ENRICH: Early MiNimally-invasive Removal of IntraCerebral Hemorrhage (ICH) (ENRICH). ClinicalTrials.gov. https:// ClinicalTrials.gov/show/NCT02880878. 2019. Accessed November 27, 2019.

16. Wang J, Doré S. Inflammation after intracerebral hemorrhage. J Cereb Blood Flow Metab 2007;27:894-908.

17. Babu R, Bagley JH, Di C, Friedman AH, Adamson C. Thrombin and hemin as central factors in the mechanisms of intracerebral hemorrhage-induced secondary brain injury and as potential targets for intervention. Neurosurg Focus 2012;32:E8.

18. Zhou Y, Wang Y, Wang J, Anne Stetler R, Yang OW. Inflammation in intracerebral hemorrhage: from mechanisms to clinical translation. Prog Neurobiol 2014;115:25-44.

19. Wang J. Preclinical and clinical research on inflammation af- ter intracerebral hemorrhage. Prog Neurobiol 2010;92:463477.

20. Aronowski J, Zhao X. Molecular pathophysiology of cerebral hemorrhage: secondary brain injury. Stroke 2011;42:17811786.

21. Keep RF, Hua Y, Xi G. Intracerebral haemorrhage: mechanisms of injury and therapeutic targets. Lancet Neurol 2012;11:720731.

22. Lawson $\sqcup$, Perry VH, Dri P, Gordon S. Heterogeneity in the distribution and morphology of microglia in the normal adult mouse brain. Neuroscience 1990;39:151-170.

23. Xiong $X Y$, Liu L, Yang $\mathrm{OW}$. Functions and mechanisms of microglia/macrophages in neuroinflammation and neurogenesis after stroke. Prog Neurobiol 2016;142:23-44.

24. Boche D, Perry VH, Nicoll JA. Review: activation patterns of microglia and their identification in the human brain. Neuropathol Appl Neurobiol 2013;39:3-18.

25. Salter MW, Beggs S. Sublime microglia: expanding roles for the guardians of the CNS. Cell 2014;158:15-24.

26. Mosser DM, Edwards JP. Exploring the full spectrum of macrophage activation. Nat Rev Immunol 2008;8:958-969.

27. Wake $H$, Moorhouse AJ, Miyamoto A, Nabekura J. Microglia: actively surveying and shaping neuronal circuit structure and function. Trends Neurosci 2013;36:209-217.

28. Haynes SE, Hollopeter G, Yang G, Kurpius D, Dailey ME, Gan $W B$, et al. The P2Y12 receptor regulates microglial activation by extracellular nucleotides. Nat Neurosci 2006;9:15121519.

29. Mildner A, Huang H, Radke J, Stenzel W, Priller J. P2Y(12) receptor is expressed on human microglia under physiological conditions throughout development and is sensitive to neuroinflammatory diseases. Glia 2017;65:375-387.

30. Ransohoff RM, Perry VH. Microglial physiology: unique stimuli, specialized responses. Annu Rev Immunol 2009;27:119-145.

31. Hidetoshi TS, Makoto $T$, Inoue K. P2Y receptors in microglia and neuroinflammation. Wiley Interdiscip Rev Membr Transp Signal 2012;1:493-501.

32. Mracsko E, Veltkamp R. Neuroinflammation after intracerebral hemorrhage. Front Cell Neurosci 2014;8:388.

33. Taylor RA, Sansing LH. Microglial responses after ischemic stroke and intracerebral hemorrhage. Clin Dev Immunol 2013;2013:746068.

34. Kanazawa M, Ninomiya I, Hatakeyama M, Takahashi T, Shimohata T. Microglia and monocytes/macrophages polarization reveal novel therapeutic mechanism against stroke. Int J Mol Sci 2017;18:E2135.

35. Zhao H, Garton T, Keep RF, Hua Y, Xi G. Microglia/macrophage polarization after experimental intracerebral hemor- 
rhage. Trans/ Stroke Res 2015;6:407-409.

36. Hu X, Leak RK, Shi Y, Suenaga J, Gao Y, Zheng P, et al. Microglial and macrophage polarization: new prospects for brain repair. Nat Rev Neurol 2015;11:56-64.

37. Hu X, Li P, Guo Y, Wang H, Leak RK, Chen S, et al. Microglia/ macrophage polarization dynamics reveal novel mechanism of injury expansion after focal cerebral ischemia. Stroke 2012;43:3063-3070.

38. Lan X, Han X, Li O, Yang OW, Wang J. Modulators of microglial activation and polarization after intracerebral haemorrhage. Nat Rev Neurol 2017;13:420-433.

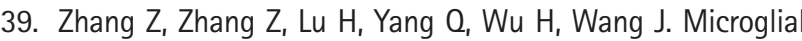
polarization and inflammatory mediators after intracerebral hemorrhage. Mol Neurobiol 2017;54:1874-1886.

40. Eggen BJ, Raj D, Hanisch UK, Boddeke HW. Microglial phenotype and adaptation. J Neuroimmune Pharmacol 2013;8:807823.

41. Wu J, Yang S, Xi G, Song S, Fu G, Keep RF, et al. Microglial activation and brain injury after intracerebral hemorrhage. Acta Neurochir Supp/ 2008;105:59-65.

42. Gomez-Nicola D, Perry VH. Microglial dynamics and role in the healthy and diseased brain: a paradigm of functional plasticity. Neuroscientist 2015;21:169-184.

43. Varnum MM, Ikezu T. The classification of microglial activation phenotypes on neurodegeneration and regeneration in $\mathrm{Al}$ zheimer's disease brain. Arch Immunol Ther Exp (Warsz) 2012;60:251-266.

44. da Fonseca AC, Matias D, Garcia C, Amaral R, Geraldo LH, Fre-

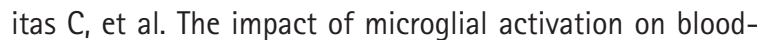
brain barrier in brain diseases. Front Cell Neurosci 2014;8:362.

45. Yang $S, C h e n ~ Y$, Deng $X$, Jiang W, Li B, Fu Z, et al. Hemoglobininduced nitric oxide synthase overexpression and nitric oxide production contribute to blood-brain barrier disruption in the rat. J Mol Neurosci 2013;51:352-363.

46. Liu DZ, Ander BP, Xu H, Shen Y, Kaur P, Deng W, et al. Bloodbrain barrier breakdown and repair by Src after thrombin-induced injury. Ann Neurol 2010;67:526-533.

47. Yao Y, Tsirka SE. Chemokines and their receptors in intracerebral hemorrhage. Trans/ Stroke Res 2012;3(Suppl 1):70-79.

48. Starossom SC, Mascanfroni ID, Imitola J, Cao L, Raddassi K, Hernandez SF, et al. Galectin-1 deactivates classically activated microglia and protects from inflammation-induced neurodegeneration. Immunity 2012;37:249-263.

49. Saijo K, Glass CK. Microglial cell origin and phenotypes in health and disease. Nat Rev Immunol 2011;11:775-787.

50. Franco R, Fernández-Suárez D. Alternatively activated microglia and macrophages in the central nervous system. Prog Neurobiol 2015;131:65-86.
51. Teng W, Wang L, Xue W, Guan C. Activation of TLR4-mediated NFKB signaling in hemorrhagic brain in rats. Mediators Inflamm 2009;2009:473276.

52. Lin S, Yin Q, Zhong Q, Lv FL, Zhou Y, Li JQ, et al. Heme activates TLR4-mediated inflammatory injury via MyD88/TRIF signaling pathway in intracerebral hemorrhage. J Neuroinflammation 2012;9:46.

53. Sansing LH, Harris TH, Welsh FA, Kasner SE, Hunter CA, Kariko K. Toll-like receptor 4 contributes to poor outcome after intracerebral hemorrhage. Ann Neurol 2011;70:646656.

54. Fang $H$, Wang PF, Zhou Y, Wang YC, Yang OW. Toll-like receptor 4 signaling in intracerebral hemorrhage-induced inflammation and injury. J Neuroinflammation 2013;10:27.

55. Zhao X, Zhang Y, Strong R, Zhang J, Grotta JC, Aronowski J. Distinct patterns of intracerebral hemorrhage-induced alterations in NF-kappaB subunit, iNOS, and COX-2 expression. $J$ Neurochem 2007;101:652-663.

56. Chhor V, Le Charpentier T, Lebon S, Oré MV, Celador IL, Josserand J, et al. Characterization of phenotype markers and neuronotoxic potential of polarised primary microglia in vitro. Brain Behav Immun 2013;32:70-85.

57. Yang J, Ding S, Huang W, Hu J, Huang S, Zhang Y, et al. Interleukin-4 ameliorates the functional recovery of intracerebral hemorrhage through the alternative activation of microglia/macrophage. Front Neurosci 2016;10:61.

58. Husemann J, Loike JD, Anankov R, Febbraio M, Silverstein SC. Scavenger receptors in neurobiology and neuropathology: their role on microglia and other cells of the nervous system. Glia 2002;40:195-205.

59. Wang $G$, Wang $L$, Sun $X G$, Tang J. Haematoma scavenging in intracerebral haemorrhage: from mechanisms to the clinic. $J$ Cell Mol Med 2018;22:768-777.

60. Zhao X, Sun G, Zhang J, Strong R, Song W, Gonzales N, et al. Hematoma resolution as a target for intracerebral hemorrhage treatment: role for peroxisome proliferator-activated receptor gamma in microglia/macrophages. Ann Neurol 2007;61:352362.

61. Xu H, Wang Z, Li J, Wu H, Peng Y, Fan L, et al. The polarization states of microglia in TBI: a new paradigm for pharmacological intervention. Neural Plast 2017;2017:5405104.

62. Cherry JD, Olschowka JA, O'Banion MK. Neuroinflammation and M2 microglia: the good, the bad, and the inflamed. J Neuroinflammation 2014;11:98.

63. Xia CY, Zhang S, Gao Y, Wang ZZ, Chen NH. Selective modulation of microglia polarization to M2 phenotype for stroke treatment. Int Immunopharmacol 2015;25:377-382.

64. Filardy AA, Pires DR, Nunes MP, Takiya CM, Freire-de-Lima CG, 
Ribeiro-Gomes FL, et al. Proinflammatory clearance of apoptotic neutrophils induces an IL-12(low)IL-10(high) regulatory phenotype in macrophages. J Immunol 2010;185:2044-2050.

65. Subramaniam SR, Federoff HJ. Targeting microglial activation states as a therapeutic avenue in parkinson's disease. Front Aging Neurosci 2017;9:176.

66. Liang Z, Wu G, Fan C, Xu J, Jiang S, Yan X, et al. The emerging role of signal transducer and activator of transcription 3 in cerebral ischemic and hemorrhagic stroke. Prog Neurobiol 2016;137:1-16.

67. Oin H, Yeh WI, De Sarno P, Holdbrooks AT, Liu Y, Muldowney MT, et al. Signal transducer and activator of transcription-3/ suppressor of cytokine signaling-3 (STAT3/SOCS3) axis in myeloid cells regulates neuroinflammation. Proc Natl Acad SciUS A 2012;109:5004-5009.

68. Lawrence T, Natoli G. Transcriptional regulation of macrophage polarization: enabling diversity with identity. Nat Rev Immunol 2011;11:750-761.

69. Nguyen H, Ramana CV, Bayes J, Stark GR. Roles of phosphatidylinositol 3-kinase in interferon-gamma-dependent phosphorylation of STAT1 on serine 727 and activation of gene expression. J Biol Chem 2001;276:33361-33368.

70. Martinez-Nunez RT, Louafi F, Sanchez-Elsner T. The interleukin 13 (IL-13) pathway in human macrophages is modulated by microRNA-155 via direct targeting of interleukin 13 receptor alpha1 (IL13Ralpha1). J Biol Chem 2011;286:17861794.

71. Sheldon KE, Shandilya H, Kepka-Lenhart D, Poljakovic M, Ghosh A, Morris SM Jr. Shaping the murine macrophage phenotype: IL-4 and cyclic AMP synergistically activate the arginase I promoter. J Immunol 2013;191:2290-2298.

72. Tsai MC, Chen WJ, Tsai MS, Ching $\mathrm{CH}_{1}$ Chuang J. Melatonin attenuates brain contusion-induced oxidative insult, inactivation of signal transducers and activators of transcription 1, and upregulation of suppressor of cytokine signaling-3 in rats. J Pineal Res 2011;51:233-245.

73. Oin H, Holdbrooks AT, Liu Y, Reynolds SL, Yanagisawa LL, Benveniste EN. SOCS3 deficiency promotes M1 macrophage polarization and inflammation. J Immunol 2012;189:34393448.

74. Koscsó $B$, Csóka $B$, Kókai $E$, Németh $Z H$, Pacher $P$, Virág $L$, et al. Adenosine augments IL-10-induced STAT3 signaling in M2c macrophages. J Leukoc Biol 2013;94:1309-1315.

75. Zhao XR, Gonzales N, Aronowski J. Pleiotropic role of PPARY in intracerebral hemorrhage: an intricate system involving Nrf2, RXR, and NF-kB. CNS Neurosci Ther 2015;21:357-366.

76. Kobayashi K, Imagama S, Ohgomori T, Hirano K, Uchimura K, Sakamoto $K_{1}$ et al. Minocycline selectively inhibits M1 polar- ization of microglia. Cell Death Dis 2013;4:e525.

77. Wasserman JK, Zhu X, Schlichter LC. Evolution of the inflammatory response in the brain following intracerebral hemorrhage and effects of delayed minocycline treatment. Brain Res 2007;1180:140-154.

78. Liddelow S, Barres B. SnapShot: astrocytes in health and disease. Cell 2015;162:1170-1170.

79. Scimemi A. Astrocytes and the warning signs of intracerebral hemorrhagic stroke. Neural Plast 2018;2018:7301623.

80. Jha MK, Lee WH, Suk K. Functional polarization of neuroglia: Implications in neuroinflammation and neurological disorders. Biochem Pharmacol 2016;103:1-16.

81. Jha MK, Jo M, Kim JH, Suk K. Microglia-astrocyte crosstalk: an intimate molecular conversation. Neuroscientist 2019;25:227240.

82. Liddelow SA, Guttenplan KA, Clarke LE, Bennett FC, Bohlen $C J$, Schirmer $L$, et al. Neurotoxic reactive astrocytes are induced by activated microglia. Nature 2017;541:481-487.

83. Lively S, Schlichter LC. Age-related comparisons of evolution of the inflammatory response after intracerebral hemorrhage in rats. Trans/ Stroke Res 2012;3(Suppl 1):132-146.

84. Tejima E, Zhao B0, Tsuji K, Rosell A, van Leyen K, Gonzalez $R G$, et al. Astrocytic induction of matrix metalloproteinase- 9 and edema in brain hemorrhage. J Cereb Blood Flow Metab 2007;27:460-468.

85. Wang J, Tsirka SE. Neuroprotection by inhibition of matrix metalloproteinases in a mouse model of intracerebral haemorrhage. Brain 2005;128(Pt 7):1622-1633.

86. Shavit E, Michaelson DM, Chapman J. Anatomical localization of protease-activated receptor- 1 and protease-mediated neuroglial crosstalk on peri-synaptic astrocytic endfeet. $J$ Neurochem 2011;119:460-473.

87. Sweeney AM, Fleming KE, McCauley JP, Rodriguez MF, Martin ET, Sousa AA, et al. PAR1 activation induces rapid changes in glutamate uptake and astrocyte morphology. Sci Rep 2017;7:43606.

88. Chiu CD, Yao NW, Guo JH, Shen CC, Lee HT, Chiu YP, et al. Inhibition of astrocytic activity alleviates sequela in acute stages of intracerebral hemorrhage. Oncotarget 2017;8:9485094861.

89. Shichita T, Sakaguchi R, Suzuki M, Yoshimura A. Post-ischemic inflammation in the brain. Front Immunol 2012;3:132.

90. Hendrix $S$, Nitsch R. The role of T helper cells in neuroprotection and regeneration. J Neuroimmunol 2007;184:100-112.

91. Kivisäkk P, Mahad DJ, Callahan MK, Trebst C, Tucky B, Wei T, et al. Human cerebrospinal fluid central memory CD4+ T cells: evidence for trafficking through choroid plexus and meninges via P-selectin. Proc Natl Acad Sci U SA 2003;100:8389-8394. 
92. Arumugam TV, Granger DN, Mattson MP. Stroke and T-cells. Neuromolecular Med 2005;7:229-242.

93. Yilmaz G, Arumugam TV, Stokes KY, Granger DN. Role of T lymphocytes and interferon-gamma in ischemic stroke. Circulation 2006;113:2105-2112.

94. Hurn PD, Subramanian S, Parker SM, Afentoulis ME, Kaler $\sqcup$, Vandenbark $A A$, et al. T- and B-cell-deficient mice with experimental stroke have reduced lesion size and inflammation. J Cereb Blood Flow Metab 2007;27:1798-1805.

95. Liesz A, Suri-Payer E, Veltkamp C, Doerr H, Sommer C, Rivest $S$, et al. Regulatory $T$ cells are key cerebroprotective immunomodulators in acute experimental stroke. Nat Med 2009;15:192-199.

96. Zhou K, Zhong Q, Wang YC, Xiong XY, Meng ZY, Zhao T, et al. Regulatory $T$ cells ameliorate intracerebral hemorrhage-induced inflammatory injury by modulating microglia/macrophage polarization through the IL-10/GSK3ß/PTEN axis. $J$ Cereb Blood Flow Metab 2017;37:967-979.

97. Xue M, Del Bigio MR. Comparison of brain cell death and inflammatory reaction in three models of intracerebral hemorrhage in adult rats. J Stroke Cerebrovasc Dis 2003;12:152-159.

98. Loftspring MC, McDole J, Lu A, Clark JF, Johnson AJ. Intracerebral hemorrhage leads to infiltration of several leukocyte populations with concomitant pathophysiological changes. $J$ Cereb Blood Flow Metab 2009;29:137-143.

99. Guo FO, Li XJ, Chen LY, Yang H, Dai HY, Wei YS, et al. Study of relationship between inflammatory response and apoptosis in perihematoma region in patients with intracerebral hemorrhage. Zhongguo Wei Zhong Bing Ji Jiu Yi Xue 2006;18:290293.

100. ladecola C, Anrather J. The immunology of stroke: from mechanisms to translation. Nat Med 2011;17:796-808.

101. Klebe D, McBride D, Flores JJ, Zhang JH, Tang J. Modulating the immune response towards a neuroregenerative peri-injury milieu after cerebral hemorrhage. J Neuroimmune Pharmacol 2015;10:576-586.

102. Luckheeram RV, Zhou R, Verma AD, Xia B. CD4 ${ }^{+} T$ cells: differentiation and functions. Clin Dev Immunol 2012;2012:925135.

103. Hwang ES, Szabo SJ, Schwartzberg PL, Glimcher LH. T helper cell fate specified by kinase-mediated interaction of T-bet with GATA-3. Science 2005;307:430-433.

104. Lazarevic V, Chen $X$, Shim JH, Hwang ES, Jang E, Bolm AN, et al. T-bet represses $T(H) 17$ differentiation by preventing Runx1-mediated activation of the gene encoding RORyt. Nat Immunol 2011;12:96-104.

105. Walker JA, McKenzie ANJ. T(H)2 cell development and function. Nat Rev Immunol 2018;18:121-133.

106. Zhu J, Guo L, Watson CJ, Hu-Li J, Paul WE. Stat6 is necessary and sufficient for IL-4's role in Th2 differentiation and cell expansion. J Immunol 2001;166:7276-7281.

107. Kebir H, Kreymborg K, Ifergan I, Dodelet-Devillers A, Cayrol R, Bernard $M_{1}$ et al. Human TH17 lymphocytes promote bloodbrain barrier disruption and central nervous system inflammation. Nat Med 2007;13:1173-1175.

108. Kleinewietfeld M, Hafler DA. The plasticity of human Treg and Th17 cells and its role in autoimmunity. Semin Immunol 2013;25:305-312.

109. Gao L, Lu Q, Huang $\sqcup$, Ruan LH, Yang JJ, Huang WL, et al. Transplanted neural stem cells modulate regulatory $T, \gamma \delta T$ cells and corresponding cytokines after intracerebral hemorrhage in rats. Int J Mol Sci 2014;15:4431-4441.

110. Mao LL, Yuan H, Wang WW, Wang YJ, Yang MF, Sun BL, et al. Adoptive regulatory t-cell therapy attenuates perihematomal inflammation in a mouse model of experimental intracerebral hemorrhage. Cell Mol Neurobiol 2017;37:919-929.

111. Murray PJ, Wynn TA. Obstacles and opportunities for understanding macrophage polarization. J Leukoc Biol 2011;89:557563.

112. Biswas SK, Mantovani A. Macrophage plasticity and interaction with lymphocyte subsets: cancer as a paradigm. Nat Immunol 2010;11:889-896.

113. Yang $Z, Y u$, Liu $Y$, Shen $H$, Lin $C$, Lin $L$, et al. Regulatory $T$ cells inhibit microglia activation and protect against inflammatory injury in intracerebral hemorrhage. Int Immunopharmacol 2014;22:522-525.

114. Ren $X$, Akiyoshi $K$, Vandenbark AA, Hurn PD, Offner $H$. Programmed death-1 pathway limits central nervous system inflammation and neurologic deficits in murine experimental stroke. Stroke 2011;42:2578-2583.

115. Mracsko E, Javidi E, Na SY, Kahn A, Liesz A, Veltkamp R. Leukocyte invasion of the brain after experimental intracerebral hemorrhage in mice. Stroke 2014;45:2107-2114.

116. Kondo A, Yamashita T, Tamura H, Zhao W, Tsuji T, Shimizu M, et al. Interferon-gamma and tumor necrosis factor-alpha induce an immunoinhibitory molecule, B7-H1, via nuclear factor-kappaB activation in blasts in myelodysplastic syndromes. Blood 2010;116:1124-1131.

117. Selenko-Gebauer N, Majdic O, Szekeres A, Höfler G, Guthann E, Korthäuer $\mathrm{U}$, et al. B7-H1 (programmed death-1 ligand) on dendritic cells is involved in the induction and maintenance of T cell anergy. J Immunol 2003;170:3637-3644.

118. Okazaki T, Chikuma S, Iwai Y, Fagarasan S, Honjo T. A rheostat for immune responses: the unique properties of PD-1 and their advantages for clinical application. Nat Immunol 2013;14:1212-1218.

119. Ostrand-Rosenberg S, Horn LA, Haile ST. The programmed 
death-1 immune-suppressive pathway: barrier to antitumor immunity. J Immunol 2014;193:3835-3841.

120. Dai S, Jia R, Zhang X, Fang Q, Huang L. The PD-1/PD-Ls pathway and autoimmune diseases. Cell Immunol 2014;290:7279.

121. Jin HT, Ahmed $R$, Okazaki T. Role of PD-1 in regulating T-cell immunity. Curr Top Microbiol Immunol 2011;350:17-37.

122. Lee $Y J$, Moon YH, Hyung KE, Yoo JS, Lee MJ, Lee IH, et al. Macrophage PD-L1 strikes back: PD-1/PD-L1 interaction drives macrophages toward regulatory subsets. Adv Biosci Biotechnol 2013;4:19-29.

123. Bodhankar $S$, Chen $Y$, Vandenbark AA, Murphy SJ, Offner $H$. PD-L1 enhances CNS inflammation and infarct volume following experimental stroke in mice in opposition to PD-1. J Neuroinflammation 2013;10:111.

124. Zhao S, Li F, Leak RK, Chen J, Hu X. Regulation of neuroinflammation through programed death-1/programed death ligand signaling in neurological disorders. Front Cell Neurosci 2014;8:271.

125. Yuan B, Huang S, Gong S, Wang F, Lin L, Su T, et al. Programmed death (PD)-1 attenuates macrophage activation and brain inflammation via regulation of fibrinogen-like protein 2 (Fgl-2) after intracerebral hemorrhage in mice. Immunol Lett 2016;179:114-121.

126. Han R, Luo J, Shi Y, Yao Y, Hao J. PD-L1 (programmed death ligand 1) protects against experimental intracerebral hemorrhage-induced brain injury. Stroke 2017;48:2255-2262.

127. Wu J, Sun L, Li H, Shen H, Zhai W, Yu Z, et al. Roles of programmed death protein 1/programmed death-ligand 1 in secondary brain injury after intracerebral hemorrhage in rats: selective modulation of microglia polarization to anti-inflammatory phenotype. J Neuroinflammation 2017;14:36.

128. Cohen JA, Chun J. Mechanisms of fingolimod's efficacy and adverse effects in multiple sclerosis. Ann Neurol 2011;69:759777.

129. Chun J, Hartung HP. Mechanism of action of oral fingolimod (FTY720) in multiple sclerosis. Clin Neuropharmacol 2010;33: 91-101.

130. Rosen $H$, Stevens RC, Hanson M, Roberts $E_{1}$ Oldstone MB. Sphingosine-1-phosphate and its receptors: structure, signaling, and influence. Annu Rev Biochem 2013;82:637-662.

131. Baeyens A, Fang V, Chen C, Schwab SR. Exit strategies: S1P signaling and T cell migration. Trends Immunol 2015;36:778787.

132. Garris CS, Blaho VA, Hla T, Han MH. Sphingosine-1-phosphate receptor 1 signalling in T cells: trafficking and beyond. Immunology 2014;142:347-353.

133. Kappos L, Radue EW, O'Connor P, Polman C, Hohlfeld R, Cal- abresi $P$, et al. A placebo-controlled trial of oral fingolimod in relapsing multiple sclerosis. N Engl J Med 2010;362:387-401.

134. Calabresi PA, Radue EW, Goodin D, Jeffery D, Rammohan KW, Reder AT, et al. Safety and efficacy of fingolimod in patients with relapsing-remitting multiple sclerosis (FREEDOMS II): a double-blind, randomised, placebo-controlled, phase 3 trial. Lancet Neurol 2014;13:545-556.

135. Groves A, Kihara Y, Chun J. Fingolimod: direct CNS effects of sphingosine 1-phosphate (S1P) receptor modulation and implications in multiple sclerosis therapy. J Neurol Sci 2013;328: 9-18.

136. Chiba K. FYY720, a new class of immunomodulator, inhibits lymphocyte egress from secondary lymphoid tissues and thymus by agonistic activity at sphingosine 1-phosphate receptors. Pharmacol Ther 2005;108:308-319.

137. Lee CW, Choi JW, Chun J. Neurological S1P signaling as an emerging mechanism of action of oral FYY720 (fingolimod) in multiple sclerosis. Arch Pharm Res 2010;33:1567-1574.

138. Tham CS, Lin FF, Rao TS, Yu N, Webb M. Microglial activation state and lysophospholipid acid receptor expression. Int J Dev Neurosci 2003;21:431-443.

139. Okada T, Kajimoto $T$, Jahangeer $S$, Nakamura S. Sphingosine kinase/sphingosine 1-phosphate signalling in central nervous system. Cell Signal 2009;21:7-13.

140. Melendez AJ. Sphingosine kinase signalling in immune cells: potential as novel therapeutic targets. Biochim Biophys Acta 2008;1784:66-75.

141. Nayak D, Huo Y, Kwang WX, Pushparaj PN, Kumar SD, Ling $E A$, et al. Sphingosine kinase 1 regulates the expression of proinflammatory cytokines and nitric oxide in activated microglia. Neuroscience 2010;166:132-144.

142. Noda H, Takeuchi H, Mizuno T, Suzumura A. Fingolimod phosphate promotes the neuroprotective effects of microglia. J Neuroimmunol 2013;256:13-18.

143. Rothhammer V, Kenison JE, Tjon E, Takenaka MC, de Lima KA, Borucki DM, et al. Sphingosine 1-phosphate receptor modulation suppresses pathogenic astrocyte activation and chronic progressive CNS inflammation. Proc Natl Acad Sci U SA 2017;114:2012-2017.

144. Qin C, Fan WH, Liu $Q$, Shang $K$, Murugan $M, W u ~ \sqcup$, et al. Fingolimod protects against ischemic white matter damage by modulating microglia toward M2 polarization via STAT3 pathway. Stroke 2017;48:3336-3346.

145. Das A, Arifuzzaman S, Kim SH, Lee YS, Jung KH, Chai YG. FTY720 (fingolimod) regulates key target genes essential for inflammation in microglial cells as defined by high-resolution mRNA sequencing. Neuropharmacology 2017;119:1-14.

146. Sucksdorff M, Rissanen E, Tuisku J, Nuutinen S, Paavilainen T, 
Rokka J, et al. Evaluation of the effect of fingolimod treatment on microglial activation using serial pet imaging in multiple sclerosis. J Nucl Med 2017;58:1646-1651.

147. Delbridge MS, Shrestha BM, Raftery AT, El Nahas AM, Haylor $J$. Reduction of ischemia-reperfusion injury in the rat kidney by FT720, a synthetic derivative of sphingosine. Transplantation 2007;84:187-195.

148. Man K, Ng KT, Lee TK, Lo CM, Sun CK, Li XL, et al. FTY720 attenuates hepatic ischemia-reperfusion injury in normal and cirrhotic livers. Am J Transplant 2005;5:40-49.

149. Hasegawa Y, Suzuki H, Sozen T, Rolland W, Zhang JH. Activation of sphingosine 1-phosphate receptor-1 by FTY720 is neuroprotective after ischemic stroke in rats. Stroke 2010;41:368374.

150. Wei Y, Yemisci M, Kim HH, Yung LM, Shin HK, Hwang SK, et al. Fingolimod provides long-term protection in rodent models of cerebral ischemia. Ann Neurol 2011;69:119-129.

151. Fu Y, Zhang N, Ren $L$, Yan $Y$, Sun N, Li YJ, et al. Impact of an immune modulator fingolimod on acute ischemic stroke. Proc Natl Acad Sci U S A 2014;111:18315-18320.

152. Zhu Z, Fu Y, Tian D, Sun N, Han W, Chang G, et al. Combination of the immune modulator fingolimod with alteplase in acute ischemic stroke: a pilot trial. Circulation 2015;132:1104-1112.

153. Lu L, Barfejani AH, Qin T, Dong Q, Ayata C, Waeber C. Fingolimod exerts neuroprotective effects in a mouse model of intracerebral hemorrhage. Brain Res 2014;1555:89-96.

154. Rolland WB, Lekic $T$, Krafft PR, Hasegawa Y, Altay O, Hartman $R$, et al. Fingolimod reduces cerebral lymphocyte infiltration in experimental models of rodent intracerebral hemorrhage. Exp Neurol 2013;241:45-55.

155. Sun N, Shen Y, Han W, Shi K, Wood K, Fu Y, et al. Selective sphingosine-1-phosphate receptor 1 modulation attenuates experimental intracerebral hemorrhage. Stroke 2016;47:18991906.

156. Fu Y, Hao J, Zhang N, Ren L, Sun N, Li YJ, et al. Fingolimod for the treatment of intracerebral hemorrhage: a 2-arm proof-of-concept study. JAMA Neuro/ 2014;71:1092-1101.

157. Wei Y, Whaley-Connell AT, Chen K, Habibi J, Uptergrove GM, Clark SE, et al. NADPH oxidase contributes to vascular inflammation, insulin resistance, and remodeling in the transgenic (mRen2) rat. Hypertension 2007;50:384-391.

158. Paoletti R, Bolego C, Poli A, Cignarella A. Metabolic syndrome, inflammation and atherosclerosis. Vasc Health Risk Manag 2006;2:145-152. 